\title{
Osteoporosis due to Glucocorticoid Use in Children with Chronic Illness
}

\author{
Leanne M. Ward \\ Department of Pediatrics, University of Ottawa and Division of Endocrinology, Children's Hospital of \\ Eastern Ontario, Ottawa, Canada
}

\section{Key Words \\ Glucocorticoids · Osteoporosis}

\begin{abstract}
Osteoporosis is increasingly recognized as a complication of chronic childhood illnesses, particularly when glucocorticoids (GCs) are necessary for treatment. Elucidation of the mechanisms leading to bone fragility in these settings requires disentanglement of the relative contributions of myriad risk factors, including disease activity, muscle weakness, immobilization, delayed growth and puberty, compromised nutrition, and osteotoxic medications. Over the years, bone mass and density evaluations by dual energy X-ray absorptiometry (DXA) have become popular for assessing bone health in children; however, such measurements are difficult to interpret because of the confounding effect of bone size and the lack of DXA-based densitometric criteria for defining osteoporosis in childhood. Recently, a new diagnostic approach for evaluation of densitometric data in children has been suggested, driven by Frost's mechanostat theory. A diagnostic algorithm based on the mechanostat theory of bone-muscle development is proposed for the characterization of bone disease in children with chronic illness. In addition to DXA-based assessments, techniques such as peripheral quantitative computerized tomography and ilial histomorphometry, for which there are pediatric reference data, are gaining ground in the characterization of skeletal changes due to chronic illness. Although these diagnostic techniques
\end{abstract}

expand our understanding of osteoporosis in children, they do not replace clinical assessment. Concrete clinical evidence for GC-induced bone fragility can be seen in spinal changes due to vertebral compression, with spinal morphometry emerging as an essential, but frequently overlooked, tool in the evaluation of children's bone health. Presently, osteoporosis treatment in the chronic illness setting remains experimental and should be restricted to clinical studies. Following an understanding of the natural history of GC-induced osteoporosis in children, randomized, placebo-controlled prevention and intervention trials will be the next step toward the development of clinical practice guidelines.

Copyright (C) 2005 S. Karger AG, Basel

\section{Introduction}

Osteoporosis, defined as atraumatic fractures associated with low bone mass and microarchitectural deterioration, is the most common metabolic bone disorder in adults, and remains a major public health problem worldwide [1, 2]. While osteoporosis has typically been considered a disease of the aging, there is increasing awareness that children are not exempt from developing the disease. Threats to bone health that are operative during the pediatric years may be particularly costly long-term, since growth and development of the skeletal system play a critical role in determining bone strength and stability in later years [3].

\section{KARGER}

Fax +4161306 1234 E-Mailkarger@karger.ch www.karger.com

\section{(C) 2005 S. Karger AG, Basel}

0301-0163/05/0645-0209\$22.00/0

Accessible online at:

www.karger.com/hre
Leanne M. Ward, MD, FRCPC

Department of Pediatrics, Room 250H, Research Institute

Children's Hospital of Eastern Ontario, 401 Smyth Rd.

Ottawa, Ont. K1H 8L1 (Canada)

Tel. +1 613737 2253, Fax +1 613738 4236, E-Mail ward_L@cheo.on.ca 


\section{Scope of the Problem}

There is a growing list of pediatric osteoporotic conditions associated with chronic disease, and studies suggest that glucocorticoid (GC) treatment plays a pivotal role in the pathogenesis of osteoporosis secondary to childhood illness [4-6]. The skeletal morbidity associated with GCs has been studied for over 70 years, since Cushing's [7] first report of endogenous cortisol excess and spontaneous vertebral compression fractures. While endogenous hypercortisolemia is a rare entity in children, exogenous GCs are commonly prescribed for their anti-inflammatory and immunosuppressive properties in the treatment of a variety of pediatric conditions, including rheumatic conditions, leukemia, and organ transplantation, to name a few. In adults, it has been estimated that up to $50 \%$ of patients on long-term ( $>1$ year) GCs demonstrate decrements in bone mineral density (BMD) that are measurable during the first 6 months of treatment [8]. The risk of fractures increases as much as 5-fold at the spine, with a doubling of the risk at nonvertebral sites [9]. Bone morbidity among children treated with GCs has been studied less extensively; however, a number of smaller studies attest to the potentially deleterious effects of GCs on bone health $[4,10]$. The largest study to evaluate the incidence of fractures among pediatric GC users was a case-control study involving over 37,000 children treated with four or more courses of oral GCs for a mean duration of 6.4 days [11]. Compared to controls, GC-treated children had an adjusted odds ratio for fracture of 1.32 (95\% confidence interval, 1.03-1.69). The purpose of this review is to provide a general overview of pediatric osteoporosis due to GC use, as a detailed description of GC-induced osteoporosis for each of the specific chronic illnesses (such as pediatric asthma and inhaled GC use) is beyond this article's scope.

\section{Pathogenesis of GC-Induced Osteoporosis}

There are myriad osteotoxic GC effects on bone and mineral metabolism that may lead to osteoporosis. Our understanding of GC-induced osteoporosis is further complicated by challenges in disentangling the relative contributions of associated risk factors for skeletal morbidity in chronic illness, including underlying disease activity, muscle weakness and immobilization, compromised nutrition and intestinal absorption, associated endocrinopathies, and the deleterious impact of other osteotoxic medications (table 1). Leong et al. [12] provided insight into the isolated effect of hypercortisolemia on the maturing skeleton in a report of a female, monozygotic twin who presented with Cushing's disease at 10 years of age. This study highlights both the direct and indirect impact of cortisol excess on various aspects of skeletal development and is discussed in the ensuing sections on pathogenesis.

\section{GC Effects on Bone Metabolism}

It is now widely held that the cardinal feature of the bone disease caused by GCs is decreased bone formation [13]. Leong et al. [12] provided clinical evidence for reduced bone formation due to chronic cortisol excess, with the Cushingoid twin manifesting complete suppression of osteocalcin during an overnight profile. Furthermore, the signature histological features of GC toxicity support a diminished effort on the part of osteoblasts, including a decrease in the bone formation rate, in the number of osteoid seams, and in trabecular wall thickness [14]. GCs are associated with a reduction in osteoblast protein synthesis, likely mediated by direct GC receptor regulation of a number of important osteoblast genes, including type I collagen, osteocalcin, osteopontin, alkaline phosphatase, and collagenase [8]. While GCs at physiological doses appear to be essential for normal osteoblast differentiation [15], at high doses GCs diminish the number of osteoblasts by promoting apoptosis [16]. Osteocytes have also been shown to undergo premature cell death, and accumulation of such cells is thought to result in osteonecrosis, another serious consequence of GC use.

While it is recognized that the major deleterious effect of GCs is on bone formation, the impact of GCs on osteoclast function has been more controversial due to conflicting findings. Clinical support for inhibition of osteoclastogenesis with long-term cortisol excess among children stems from reports of reduced bone resorption markers in Cushing's disease, with a rise in resorption indices following resolution of hypercortisolemia [12]. Furthermore, ilial histomorphometric evaluations in children with fractures due to chronic GC exposure show a significant reduction in osteoclast surface/bone surface with low bone turnover [17] (table 2). Weinstein et al. [16] also reported that high-dose prednisolone was associated with impaired osteoclastogenesis in mice. On the other hand, the discovery and characterization of the osteoprotegerin (OPG)/RANK-ligand/RANK paracrine triad in skeletal biology has expanded our concepts of the GC effect on bone. RANK-ligand binds to RANK with high affinity and together with macrophage colony-stimulating factor, stimulates osteoclastogenesis. The third molecule, OPG, exerts a strong inhibitory effect on osteoclas- 
Table 1. Medical therapies which may be administered at the time of glucocorticoid treatment, compounding the deleterious effect on bone health

\begin{tabular}{|c|c|c|}
\hline Agent & Proposed osteotoxic effect (direct or indirect) & Ref. \\
\hline Methotrexate & $\begin{array}{l}\text { Uncertain. Proposed mechanisms include impaired } \\
\text { protein synthesis by osteoblasts, interference with } \\
\text { vitamin C metabolism }\end{array}$ & 43,100 \\
\hline Cyclosporine & $\begin{array}{l}\text { Uncertain. High-turnover state with increased } \\
\text { resorption has been observed }\end{array}$ & 101 \\
\hline Heparin & $\begin{array}{l}\text { Uncertain. Proposed mechanisms include inhibition } \\
\text { of renal 1- } \alpha \text {-hydroxylase activity with reductions in } \\
\text { circulating levels of } 1,25 \text {-dihydroxyvitamin D and } \\
\text { concomitant increases in PTH; direct drug effect on } \\
\text { bone tissue with increased resorption and decreased } \\
\text { formation, affecting primarily cancellous bone }\end{array}$ & 102 \\
\hline Radiotherapy & $\begin{array}{l}\text { Hormonal deficiencies (growth hormone, central } \\
\text { or peripheral hypogonadism), avascular necrosis, } \\
\text { muscle atrophy }\end{array}$ & 103 \\
\hline $\begin{array}{l}\text { Medroxy- } \\
\text { progesterone acetate }\end{array}$ & Central hypogonadism & 104 \\
\hline GnRH analogs & Central hypogonadism & \\
\hline $\begin{array}{l}L \text {-thyroxine } \\
\text { suppressive therapy }\end{array}$ & $\begin{array}{l}\text { Osteoblast-mediated } \mathrm{T}_{3} \text { activation of osteoclasts, } \\
\text { resulting in bone resorption }\end{array}$ & $106-108$ \\
\hline Anticonvulsants & $\begin{array}{l}\text { Reduced trabecular bone, but compensatory } \\
\text { increased cortical bone, with preservation of the } \\
\text { absolute bone mass }\end{array}$ & 109 \\
\hline
\end{tabular}

GnRH = Gonadotropin-releasing hormone; $\mathrm{PTH}$ = parathyroid hormone. togenesis and skeletal resorption by acting as a decoy receptor for RANK-ligand. In vitro studies have shown a profound inhibition of OPG by GCs, with subsequent stimulation of RANK-ligand expression by human osteoblasts [18]. It is suggested that this may be the mechanism by which GCs stimulate osteoclastogenesis, leading to a hyper-resorptive state. In some clinical studies of exogenous GC excess, serum levels of OPG have been shown to be reduced, in concert with the in vitro observations $[19,20]$. However, OPG levels were found to be elevated in a report of patients with Cushing's syndrome [21]. To reconcile these conflicting findings, it has been suggested that the OPG response may be different in exogenous versus endogenous cortisol excess. It has also been hypothesized that osteoclast stimulation may occur during an early, transient phase of GC-induced skeletal toxicity, followed by inhibition of bone resorption if GC use is prolonged [13]. This process may represent a compensatory response to prevent further bone loss in long-standing cortisol excess, an explanation which fits with the biphasic pattern of bone loss observed in adults on long-
Table 2. Quantitative ilial histomorphometry in children* with glucocorticoid-induced osteoporosis secondary to chronic illness

\begin{tabular}{lr}
\hline Parameter & \multicolumn{1}{c}{$\begin{array}{l}\text { Results** } \\
(\mathrm{n}=8)\end{array}$} \\
\hline Structural & \\
$\quad$ Core width, mm & $6.8(79 \%)$ \\
$\quad$ Cortical width, $\mu \mathrm{m}$ & $618.0(62 \%)$ \\
$\quad$ Bone volume per tissue volume, $\%$ & $17.9(70 \%)$ \\
Formation & \\
$\quad$ Osteoid thickness, $\mu \mathrm{m}$ & $4.5(68 \%)$ \\
$\quad$ Osteoid surface per bone surface, $\%$ & $12.0(60 \%)$ \\
$\quad$ Mineralizing surface per bone surface, $\%$ & $8.7(74 \%)$ \\
$\quad$ Mineral apposition rate, $\mu \mathrm{m} /$ day & $0.9(94 \%)$ \\
Resorption & $0.5(44 \%)$ \\
$\quad$ Osteoclast surface per bone surface, $\%$ &
\end{tabular}

* Subjects presented with the following diagnoses: nephrotic syndrome $(n=2)$; systemic lupus erythematosis $(n=2)$, Duchenne's muscular dystrophy $(\mathrm{n}=2)$, leukemia $(\mathrm{n}=1)$, Wegener's granulomatosis $(\mathrm{n}=1)$.

** Expressed as the median of the raw values and as the percent of the healthy average for age (normative data taken from [105]). 
term steroids (characterized by a rapid, initial phase of loss in the first few months of GC use, followed by a slower rate of loss thereafter). Further studies are needed to determine the validity of these proposed mechanisms.

\section{GC Effects on Vitamin and Mineral Metabolism}

$\mathrm{GC}$ administration is associated with diminished intestinal calcium absorption and increased renal tubular calcium excretion, resulting in a negative calcium balance [8]. If the degree of hypercalcuria is marked, nephrocalcinosis may result [12]. Mild, secondary hyperparathyroidism has been demonstrated in some $[12,22]$, but not all [23], studies of patients exposed to chronic cortisol excess. To date, the relative contribution of hyperparathyroidism in the development of GC-induced osteoporosis remains controversial, but a recent review of the issue in adults has concluded that the effects are likely to be minor [24]. There has been no convincing indication of clinically relevant changes in vitamin D metabolism during GC administration [25]. When 25-hydroxyvitamin D levels are low in GC-treated patients, this finding likely reflects decreased vitamin D intake and lack of sun exposure.

\section{GC Effects on Growth, Muscle Development, and Puberty}

The growth-retarding effect of GCs is well known in children, due to a direct effect of GCs on chondrocyte function [26] and an indirect effect on growth through inhibition of the growth hormone/insulin growth factor 1 axis [12, 27]. Long-term GC administration may also result in myopathy [28]. Therefore, GCs reduce two critical mechanical challenges (muscle forces and changes in bone length) that normally stimulate bone mineral accrual during development [29].

Children with chronic illness may experience delays in pubertal maturation even in the absence of GCs [30, 31], implicating the underlying systemic condition. The patient with Cushing's disease described by Leong et al. [12] provided support for a direct effect of GCs on pubertal progression. This patient manifested a delay in bone age and pubertal signs, with hormonal evidence of central hypogonadism. In addition to inhibition of gonadotrophins, adrenal and gonadal sex steroid production may also be blunted by GCs [32, 33]. In girls, when sexual development proceeds normally, estrogen serves to enhance bone tissue response to mechanical strain by lowering the bone's 'mechanostat set-point' at the endosteal bone surface [34]. With rising estrogen concentrations, the endosteum is sensitized to mechanical strain, leading to endocortical apposition at many skeletal sites (thought to rep-



Fig. 1. Vertebral compression following 5 years' deflazacort use, given to retard deterioration in muscle strength in a 13-year-old patient with Duchenne's muscular dystrophy.

resent an estrogen-dependent bone reservoir to be tapped during pregnancy and lactation). In boys, testosterone plays a critical role in muscle development, which in turn is a potent stimulus for mineral accrual [29]. The hypogonadal effect of GCs may interfere with these adaptive processes of puberty to foster bone strength.

\section{Skeletal Manifestations of GC Toxicity and the Potential for Recovery}

GCs toxicity appears to have a predilection for trabecular bone, which has a higher metabolic activity than cortical bone, and thus may be more sensitive to the deleterious effect of steroids [35]. This is supported by the propensity of GCs to affect the spine (fig. 1). 
The temporal pattern of bone mass changes in adults with GC-induced osteoporosis appears to be biphasic, with a precipitous drop observed in the first 6-12 months of therapy, followed by a gradual, but sustained, loss in subsequent years [36, 37]. Among adults, there is potential for restitution of bone mass following discontinuation of GC therapy, with a concomitant reduction in fracture risk [38, 39]. Studies have shown that the greatest reduction in bone mineral content (BMC) and BMD among children with leukemia occurred during the first 6-8 months of chemotherapy $[4,10]$, similar to the potent GC effect on bone seen in the adult population. Furthermore, these findings were associated with an increased fracture risk both during [4] and following [10] leukemia treatment.

The effect of age and duration of the insult on the potential for bone mass recovery in young subjects raises an important issue for clinical care. This was recently explored by Gafni et al. [40], who showed that short-term, high-dose dexamethasone administration to 5-week-old rabbits resulted in greatly reduced tibial bone mass. Complete recovery through endochondral bone formation was then achieved by 16 weeks, following cessation of dexamethasone. These data suggest that significant, but temporary, insults to the skeleton early in life may not ultimately affect bone strength because much of the young skeleton is replaced entirely through bone growth. On the other hand, insults that affect skeletal health in the long term, or during the later pediatric years when growth potential is less, may be associated with persistent skeletal disease [5, 41]. Studies of GC-treated children with systemic lupus erythematosis and nephrotic syndrome [42] suggest that if a full recovery from underlying disease is achieved prior to puberty, obviating the need for ongoing $\mathrm{GC}$ use, normalization of BMD may be possible. On the other hand, patients who continue to receive long-term steroids, or whose GC threat to bone health persisted into the pubertal years, may not have similar potential for recovery [4]. Halton et al. [4] showed, among children who were prepubertal at diagnosis with leukemia, that changes in spinal BMC and BMD were not significantly different from the age- and gender-matched mean after 2 years of leukemia therapy, while pubertal children did show significant decrements in these parameters. On the other hand, Mandel et al. [43] reported that for patients with a history of childhood leukemia, a low femoral neck BMD at a mean of 10.1 years from diagnosis was not related to chronological age or age at diagnosis, but to higher doses of GCs and also to methotrexate. The age or pubertal stage after which potential for restitution of bone mass is lost in the various childhood illnesses, and the relative contribution of associated risk factors, requires further study through longitudinal research programs.

In clinical care, it is useful to know the fracture risk associated with a given BMD, a fact which has been worked out for some adult populations. For example, a 6-fold increase in the risk of vertebral fracture was associated with a decrement of $\leq 1$ standard deviation (SD) in lumbar spine BMD among GC-treated postmenopausal women with rheumatoid arthritis [44], compared to a 2- to 3-fold increased risk among women with postmenopausal osteoporosis alone [45]. It has been proposed that alterations in bone quality independent of BMD may explain these observations. Epidemiological studies to determine fracture risk for a given BMD (or change in BMD) among children receiving GCs are not available, although such data are emerging among children without medical diagnoses or treatments. Jones et al. [46] showed in healthy girls that a $1 \mathrm{SD}$ reduction in areal BMD compared to the age-matched mean was associated with an almost 2-fold increased risk of forearm fractures. The fracture risk associated with a given BMD in children with various chronic illnesses remains an important area for further study.

Since BMD determination by dual energy X-ray absorptiometry (DXA) in children poses additional challenges in interpretation, largely due to the effects of changes in bone size and body composition (fat mass), and since bone strength is determined not only by bone mass/density but by bone geometry and quality, recent attention has turned to the exploration of alternative methods for characterization of bone health and disease among children receiving GCs. For example, Leonard et al. [47] reported peripheral quantitative computerized tomography (pQCT) results at the distal tibia in 68 patients with incident Crohn's disease, 31 of whom were re-evaluated 12 months later. At diagnosis, significant reductions were observed in cortical cross-sectional area, stressstrain index and muscle cross-sectional area. After 12 months of Crohn's therapy, muscle cross-sectional area increased, while further deterioration in cortical crosssectional area and stress-strain index were noted.

Insight into the mechanisms of bone fragility in children with GC-induced osteoporosis can also be gleaned from ilial bone histomorphometric studies (table 2; fig. 2). Eight pediatric patients with chronic systemic illness (mean age 13.3 years, range 7.4-17.6), all of whom developed painful vertebral compression due to chronic GC use, underwent ilial sampling following dual tetracycline labeling [17]. Histomorphometry revealed low bone turnover with reduced formation and resorption indices, reduced cancellous bone volume and thinning of the corti- 


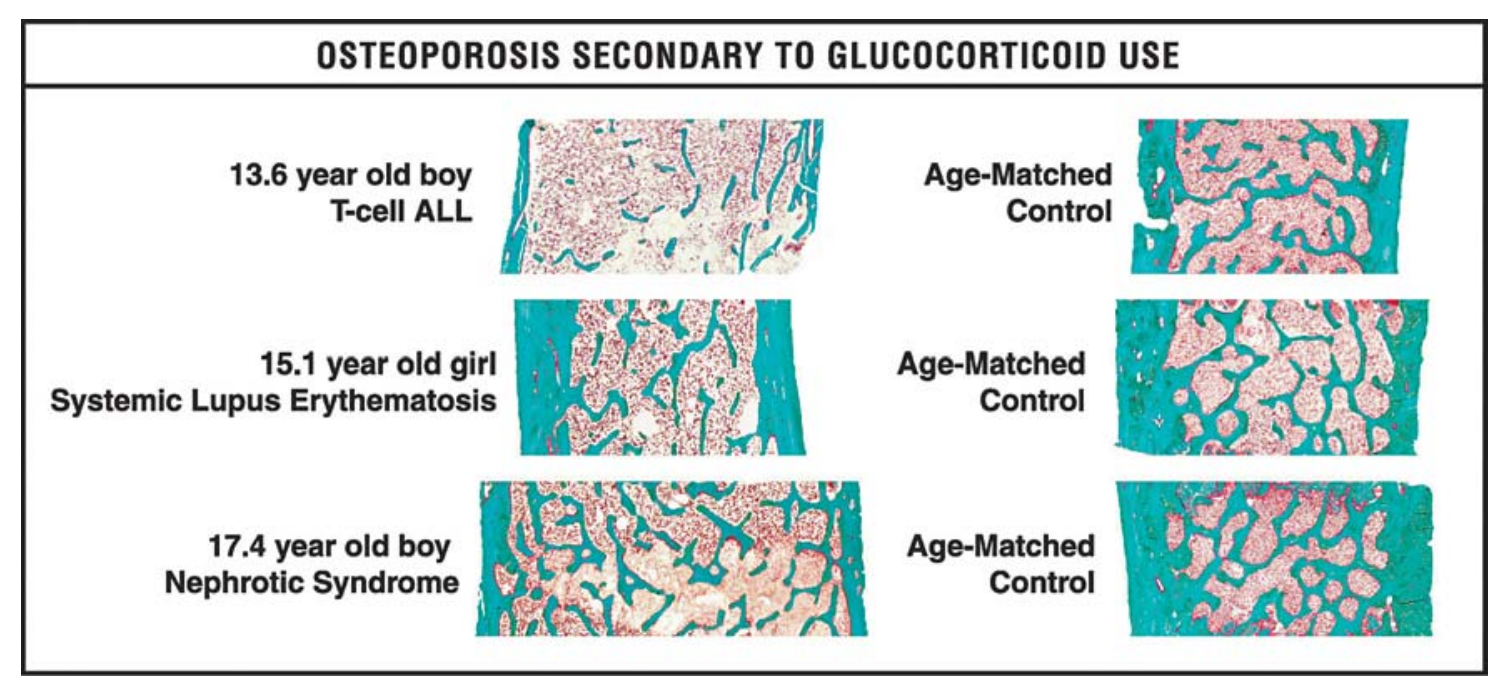

Fig. 2. Qualitative ilial histomorphometry in children with glucocorticoid-induced osteoporosis, with results compared to healthy controls. T-cell ALL = T-cell acute lymphoblastic leukemia.

ces as potential mechanisms for bone fragility in these advanced cases. At the same time, the average sizecorrected (volumetric) BMD at the lumbar spine was -1.8 SD below the mean (range $-3.0-0$ ), highlighting that children with bone tissue abnormalities associated with GC-induced skeletal fragility may have BMD values within what would typically be considered the 'normal range' according to a Gaussian curve.

\section{Impact of Dose, Frequency, and Route of GC Treatment on Bone Health}

Studies in adults have shown that the magnitude of the GC effect on bone appears to be dose dependent [9]. However, it remains unsettled whether low doses cause bone loss in all patients. The concept of a threshold dose is controversial in the adult field, as even low doses of GCs affect skeletal metabolism [48]. In adults with rheumatoid arthritis, it appears from a clinical perspective that a dose of prednisone $<5 \mathrm{mg} /$ day is relatively safe [ 49 , 50]. Alternate day steroid use does not appear to reduce the skeletal effect compared to daily administration, at higher doses [51]. The lowest-dose threshold for children, if it exists, has not been determined. Deflazacort, an oral steroid derivative, has a bone-sparing effect when compared to prednisone or methylprednisone in the short term $[52,53]$. However, a report of 46 boys with Duchenne's muscular dystrophy who received deflazacort over a 4-year period showed that 26/46 (52\%) of the boys suffered 37 fracture events [54]. Of the 37 fractures, 39\% were vertebral compression fractures, while the rest were long bone fractures. Significant decrements in bone mass were also observed over the study period in these boys who were on deflazacort. Among boys with Duchenne's who did not receive steroids, Larson and Henderson [55] observed that $44 \%$ of patients had sustained fractures, the majority of which occurred in the lower extremities. None of these patients were noted to have vertebral compression. These results suggest that the osteotoxic effect of deflazacort appears to exacerbate the underlying predisposition for osteoporosis in boys with Duchenne's muscular dystrophy, and has a predilection for the spine. Inhaled GCs have fewer systemic, including skeletal, effects compared to oral or intravenous therapy [56-58], unless they are administered at high doses [59, 60].

While studies support reductions in BMD and BMC during GC treatment for children [61-63], not all studies are consistent with a definite GC effect on bone health. It has been reported that despite receiving an average prednisone dose of 23,000 mg administered over a mean of 4.4 years (almost triple the adult GC threshold dose of prednisone $5 \mathrm{mg}$ daily), children with GC-sensitive nephrotic syndrome did not demonstrate deficits in BMC of the spine or whole body relative to age, bone size, sex, or degree of maturation [64]. The study patients had a lower BMC than controls only after correction for body mass index, and only at the lumbar spine. The investigators hypothesized that the intermittent nature of the pulse GC therapy in this disease allowed the growing skeleton 




Fig. 3. Algorithm for assessment of pediatric osteoporosis in the context of chronic illness (proposed by Schoenau et al. [65] for pQCT, and adapted to DXA by Crabtree et al. [66]; ${ }^{\circ}$ American Society for Bone and Mineral Research). BMC = Bone mineral content.

to tolerate transient reductions in bone formation through recovery during periods of disease remission and GC withdrawal. It should be noted that these results may be unique to nephrotic syndrome, where children are typically well-nourished, ambulatory, and exempt from the bone tissue effects of inflammatory mediators [64]. Despite these reassuring results, the limitations of the study's design leave a number of issues unsettled. Since these data are cross-sectional, they do not address the pattern of bone mass and density development in individual patients. Furthermore, bone mass and density by DXA were the only indices assessed, with further studies needed to evaluate bone strength more comprehensively.

\section{Approach to Diagnosis and Treatment}

The characterization of bone health in children has traditionally been based on DXA measurement of BMD or BMC. However, this approach is fraught with difficulties, given that BMD criteria for the diagnosis of osteoporosis in children do not exist (i.e., the fracture threshold for a given BMD in this setting is unknown presently). The simple use of Gaussian curve cutoffs for defining bone health and disease in GC-treated patients is sometimes used but is not sensible, since children with BMD values that are within 2 SD of the age- and gender-matched mean may still develop vertebral compression, and children at the limits of the Gaussian curve may not have a bone health abnormality. BMD evaluations by DXA are further complicated by the need to consider bone size, the stage of maturation, and the effect of changes in fat mass on the DXA results, all of which can be significantly abnormal in
GC-treated children. Given these issues, an understanding of the relationship between skeletal morbidity due to GC use and DXA parameters of bone health must be further delineated in children before treatment decisions based solely on DXA-based parameters will be justified.

Recently, a new diagnostic approach to evaluation of densitometric data in children has been suggested [65] and subsequently applied to DXA parameters [66]. This approach is driven by Frost's mechanostat theory [67], and proposes that the skeleton continuously adapts its strength in order to maintain the strains that result from physiological loads close to a set-point. Since muscle contractions provide the largest physiological load, a close relationship between bone strength and muscle force/size is expected, and indeed has been corroborated in pediatric clinical studies [65]. A diagnostic algorithm based on the mechanostat theory of bone-muscle development is proposed for the characterization of bone disease in children with chronic illness, and could be implemented for children taking GCs. Measures of height, muscle force/size (such as muscle cross-sectional area by pQCT or lean body mass by DXA) and BMC at a corresponding location are required. If $\mathrm{BMC}$ is lower than expected for muscle force/size, a 'primary bone defect' is diagnosed. If muscle force or size is too low for height, even if BMC is adapted adequately to the decreased mechanical challenge, this means that bone mass and presumably strength are still too low for body height, and therefore a 'secondary bone defect' is diagnosed. If muscle force/size is abnormally low and BMC is lower than expected for a normal muscle-bone relationship, a 'mixed (primary and secondary) bone defect' is present (fig. 3). This algorithm is useful in the clinical 
setting and will facilitate understanding of the relative contribution of various risk factors for compromised bone health in the GC-treated patient.

Biochemical markers of bone metabolism do not facilitate the diagnosis of osteoporosis, but may be useful to monitor responses to GC-induced osteoporosis treatment. pQCT and ilial histomorphometry, while highly informative, are typically reserved for research settings. As such, to date, the diagnosis of GC-induced osteoporosis remains largely a clinical one, and will be said to exist when the child's skeleton has not been able to withstand its mechanical challenges, resulting in fragility fractures. Recently, it has been shown that quantification of vertebral dimensions (morphometry) has clinical utility for monitoring of osteoporosis treatment response [68]. Given that vertebral changes due to compression fractures may be present before significant alterations in BMD by DXA are evident in GC-treated children [69], evaluation of spinal changes during GC treatment can be useful for early identification of osteoporosis.

A comprehensive assessment of all risk factors should be undertaken before initiating a treatment plan for pediatric patients with GC-induced osteoporosis. As a general principle for patients with GC-responsive diseases, the minimally effective dose to treat disease activity should be prescribed, and topical or inhaled therapies should be offered when appropriate. Hypogonadism, inadequate nutrition (including calcium and vitamin $\mathrm{D}$ intake), growth hormone deficiency, malabsorption, and impaired mobility should also be addressed as part of the overall management plan.

With established osteoporosis (i.e., fragility fractures), these treatment measures are frequently inadequate, and pediatric GC-induced osteoporosis patients often have persistent pain and vertebral fractures, despite attempts to quell disease activity and restore nutrition, mobility, and the hormonal milieu. Trials of rescue therapy (secondary prevention) in adults, once osteoporosis is established, have led to the study of calcium, vitamin D (calciferol), vitamin D analogs (calcitriol and alphacalcidiol), calcitonin, hormone replacement, and bisphosphonates. Calcium and vitamin D have not been shown to be effective in reducing fracture rates among adults on long-term GCs [70]. Studies of sex hormones, vitamin D analogs and calcitonin have not been sufficiently powered to address fracture incidence, though BMD has been positively affected in a number of studies [71-74]. Among adults, none of these agents appear to be as effective as bisphosphonates, where evidence of benefit has been more consistently documented $[75,76]$.
Unlike in adults, medical intervention for GC-induced osteoporosis in children remains virtually unchartered in the literature to date, with studies of calcitonin [77], alendronate [78], pamidronate [79-81], and growth hormone [82] restricted to small numbers of patients, observational studies, and case-control trials. The greatest experience with osteoporosis treatment in children comes from the use of intravenous, cyclical pamidronate in children with osteogenesis imperfecta (OI, a congenital bone fragility condition). Pamidronate is a member of the bisphosphonate group and a potent inhibitor of bone resorption through inhibition of protein prenylation [83, 84], a process which renders the osteoclast inactive. Intravenous pamidronate has been shown in a number of observational and casecontrol studies to benefit children with moderate-to-severe OI by improving pain, mobility, grip force, bone mass, and by decreasing the number of fractures [85-90]. The beneficial effect of pamidronate at the bone tissue level appears to be due to expansion of cortical width through selective inhibition of resorption during the modeling process [91].

Common adverse effects observed in the majority of pediatric patients who have received intravenous pamidronate have been a transient low-grade fever and flu-like symptoms (known as the 'acute phase reaction') [92]. Bisphosphonates suppress bone resorption and turnover, leading to reduced levels of serum alkaline phosphatase with decreased production of collagen breakdown products (due to a reduction in bone turnover). Asymptomatic hypocalcemia and hypophosphatemia are also typical findings. Anterior uveitis and scleritis are rare complications, and transient decreases in lymphocyte counts have also been observed [93].

Theoretical concerns about the effect of bisphosphonate therapy on the growing skeleton have not been confirmed after a decade of clinical and histological observation [93, 94]. Zeitlin et al. [95] found that long-term, cyclical intravenous pamidronate therapy was associated with significant height gain in OI types I, III, and IV. When treatment is given before closure of the epiphyses, sclerotic lines appear at the distal metaphyses of long bones. Despite this finding, skeletal maturation proceeds at a normal rate [93]. The importance of judicious use of pamidronate for patients with confirmed diagnosis of bisphosphonate-response disease and of adherence to published protocols for dosing of the drug and scrutiny of bone development and metabolism [96] is highlighted in the recent case published by Whyte et al. [97]. In this report, high doses of intravenous pamidronate were given over a short interval to a young boy with an unclearly defined condition characterized predominantly by hyperphosphatasemia. 
This patient, who received excessive doses of pamidronate between the ages of 7 and 10 years, not surprisingly developed an osteopetrotic phenotype including 'cartilage bars' on transiliac bone biopsy. These findings were due to delayed removal of calcified primary spongiosa by osteoclasts resulting from excessive doses of pamidronate over a short interval, which was administered without close monitoring of the patient's bone development and metabolism.

Positive reports of intravenous pamidronate in children with OI have led to interest in the more convenient oral bisphosphonates. A pharmacokinetics study of oral, weekly alendronate in children with mild OI recently showed that the absorption was $<1 \%$, comparable to adult

Table 3. Practice points

Osteoporosis is increasingly recognized as a complication of chronic childhood illness, particularly when GCs are necessary for treatment.

GCs exert their deleterious effect on bone through a direct impact on osteoblast (and possibly osteoclast) function, and by disturbing mineral metabolism, growth, muscle development, and progression through puberty.

At present, the diagnosis of osteoporosis in children with chronic illness remains a clinical one, existing when low-trauma fractures are present in association with reduced bone mass. Vertebral morphology is an important (and frequently overlooked) tool for assessment of such fragility fractures, particularly since steroids have a predilection for the spine.

BMD (by DXA) criteria for the diagnosis of osteoporosis in children do not currently exist. However, DXA-based parameters can be useful to understand the patient's bone health status. By applying an algorithm that is based on Frost's mechanostat theory, a primary, secondary, or mixed bone defect can be determined $[65,66]$.

Spontaneous recovery from GC-induced osteoporosis may be possible, depending upon the timing and duration of the steroid insult, and on the status of associated risk factors.

Before consideration is given to experimental therapies in the treatment of GC-induced osteoporosis, a comprehensive assessment and treatment of all associated risk factors needs to be carried out. Such risk factors include inadequate nutrition, impaired mobility, and endocrine disorders (delayed growth and puberty).

Bisphosphonates hold promise for the prevention and treatment of GC-induced osteoporosis in children; however, their use should be restricted to research programs in centers which are specialized in the diagnosis and treatment of pediatric osteoporosis due to chronic illness.

$\mathrm{GC}=$ Glucocorticoid; $\mathrm{BMD}=$ bone mineral density; DXA = dual-energy X-ray absorptiometry.

GC-Induced Osteoporosis in Children studies [98], and that there were documented side effects similar to the acute phase reaction observed with intravenous pamidronate. Alpadronate, administered as weekly tablets to children with severe OI, was shown to positively impact on bone mass, density, and fracture rates, although reshaping of compressed vertebrae and mobility were unchanged after 2 years' treatment in this randomized, controlled trial of 34 patients [99].

The clinical benefit and safety profile of pamidronate for the treatment of OI, and preliminary reports of oral and intravenous bisphosphonates in children with other osteoporotic conditions, support the development of randomized, controlled trials in children with GC-induced osteoporosis to determine their efficacy and safety in this population. However, any such treatment with bisphosphonates should be recognized as experimental at the present time, administered within the context of research programs, and restricted to specialized centers with expertise in the diagnosis and treatment of pediatric osteoporosis. Furthermore, informed consent should be obtained in all patients prior to therapy. The safety and efficacy of newer compounds on the horizon, such as parathyroid hormone and vitamin D analogs, have not been determined in children.

\section{Table 4. Research directions}

There is a need for prospective, natural history studies which determine the pattern and frequency of fractures among children receiving GCs, and which evaluate the relative contributions of associated risk factors. Such studies are also required to determine the relationship between DXA parameters and fractures, with long-term follow-up of children who start, and subsequently cease, steroids.

Establishment of collaborative health registries would facilitate the natural history study of patients with steroid-requiring diseases, and would be of particular benefit for rarer illnesses, where patient numbers are small.

Studies of techniques beyond DXA-determined BMD for the characterization of bone health in children are needed to further our understanding of pathogenetic mechanisms. To this end, ilial histomorphometry, vertebral morphometry, and pQCT are emerging as useful tools.

Following an understanding of the natural history of GC-induced osteoporosis in children, randomized, placebo-controlled prevention and intervention studies on large numbers of patients will be the next step toward development of comprehensive clinical practice guidelines.

GC = Glucocorticoid; DXA = dual-energy X-ray absorptiometry; $\mathrm{BMD}=$ bone mineral density; $\mathrm{pQCT}=$ peripherial quantitative computerized tomography. 
Summary and Future Horizons (tables 3, 4)

The study and treatment of children with GC-induced osteoporosis presents a particular challenge to pediatric researchers and clinicians. The investigative hurdles to overcome, for the design and execution of effective observation and treatment studies, stem from the tremendous heterogeneity and complexity of the underlying conditions associated with GC use, from the fact that children with GC-induced osteoporosis are often unwell, and from the loss of statistical power due to potentially small patient numbers for certain disease categories. At present, there is considerable need for prospective studies of fracture pattern and incidence and for charting of additional bone health indices (pain, mobility, bone strength, and geometry) in the various disease categories, both during and after GC use. At the same time, there is a persistent need for the use of techniques beyond BMD to characterize bone health and disease in children with chronic illness, including spinal morphometry, pQCT, and ilial histomorphometry. Following an understanding of the natural history of GC-induced osteoporosis in children, randomized, placebo-controlled prevention and intervention trials on large numbers of patients will be the next step toward the development of comprehensive practice guidelines.

\section{Acknowledgments}

I would like to thank Dr. Francis H. Glorieux and Dr. Frank Rauch at the Shriners Hospital for Children in Montréal for the processing and analyses of the ilial histomorphometric samples, and Guylaine Bedard, also at the Shriners Hospital, for figures 1 and 2 .

\section{References}

$\checkmark 1$ Cooper C, Johnell O, Lips P, Melton LJ, Kanis JA: The global burden of vertebral fracture. J Bone Miner Res 2002;17:F286.

2 Ray NF, Chan JK, Thamer M, Melton LJ 3rd: Medical expenditures for the treatment of osteoporotic fractures in the United States in 1995: report from the National Osteoporosis Foundation. J Bone Miner Res 1997;12:2435 .

3 Parfitt AM: Prevention of osteoporosis is a pediatric responsibility. Osteologicky Bulletin, 1997, pp 66-70.

4 Halton JM, Atkinson SA, Fraher L, Webber C, Gill GJ, Dawson S, Barr RD: Altered mineral metabolism and bone mass in children during treatment for acute lymphoblastic leukemia. J Bone Miner Res 1996;11:1774-1783.

-5 Trapani S, Civinini R, Ermini M, Paci E, Falcini F: Osteoporosis in juvenile systemic lupus erythematosus: a longitudinal study on the effect of steroids on bone mineral density. Rheumatol Int 1998; 18:45-49.

6 Lettgen B, Jeken C, Reiners C: Influence of steroid medication on bone mineral density in children with nephrotic syndrome. Pediatr Nephrol 1994;8:667-670.

7 Cushing H: The basophil adenomas of the pituitary body and their clinical manifestations (pituitary basophilism). Bull Johns Hopkins Hosp 1932;50:137-195.

-8 Reid IR: Glucocorticoid effects on bone. J Clin Endocrinol Metab 1998;83:1860-1862.

-9 Sambrook PN: Corticosteroid osteoporosis: practical implications of recent trials. J Bone Miner Res 2000;15:1645-1659.
0 van der Sluis IM, van den Heuvel-Eibrink MM, Hahlen K, Krenning EP, de Muinck Keizer-Schrama SM: Altered bone mineral density and body composition, and increased fracture risk in childhood acute lymphoblastic leukemia. J Pediatr 2002;141:204-210.

11 van Staa TP, Cooper C, Leufkens HG, Bishop $\mathrm{N}$ : Children and the risk of fractures caused by oral corticosteroids. J Bone Miner Res 2003; 18:913-918.

12 Leong GM, Mercado-Asis LB, Reynolds JC, Hill SC, Oldfield EH, Chrousos GP: The effect of Cushing's disease on bone mineral density, body composition, growth, and puberty: a report of an identical adolescent twin pair. J Clin Endocrinol Metab 1996;81:1905-1911.

13 Manolagas SC: Cell number versus cell vigor - what really matters to a regenerating skeleton? Endocrinology 1999; 140:4377-4381.

14 Chavassieux P, Pastoureau P, Chapuy MC, Delmas PD, Meunier PJ: Glucocorticoid-induced inhibition of osteoblastic bone formation in ewes: a biochemical and histomorphometric study. Osteoporos Int 1993;3:97-102.

15 Wong MM, Rao LG, Ly H, Hamilton L, Tong J, Sturtridge W, McBroom R, Aubin JE, Murray TM: Long-term effects of physiologic concentrations of dexamethasone on human bone-derived cells. J Bone Miner Res 1990;5:803-813.

16 Weinstein RS, Jilka RL, Parfitt AM, Manolagas SC: Inhibition of osteoblastogenesis and promotion of apoptosis of osteoblasts and osteocytes by glucocorticoids. Potential mechanisms of their deleterious effects on bone. $\mathrm{J}$ Clin Invest 1998;102:274-282.

17 Ward LM, Rauch F, White C, Glorieux FH Ilial histomorphometry in children with osteoporosis secondary to chronic illness. J Bone Miner Res 2004;19:SU522.
18 Hofbauer LC, Gori F, Riggs BL, Lacey DL, Dunstan CR, Spelsberg TC, Khosla S: Stimulation of osteoprotegerin ligand and inhibition of osteoprotegerin production by glucocorticoids in human osteoblastic lineage cells: potential paracrine mechanisms of glucocorticoid-induced osteoporosis. Endocrinology 1999;140: 4382-4389.

19 Sasaki N, Kusano E, Ando Y, Yano K, Tsuda E, Asano Y: Glucocorticoid decreases circulating osteoprotegerin (OPG): possible mechanism for glucocorticoid induced osteoporosis. Nephrol Dial Transplant 2001;16:479-482.

20 von Tirpitz C, Epp S, Klaus J, Mason R, Hawa G, Brinskelle-Schmal N, Hofbauer LC, Adler G, Kratzer W, Reinshagen M: Effect of systemic glucocorticoid therapy on bone metabolism and the osteoprotegerin system in patients with active Crohn's disease. Eur J Gastroenterol Hepatol 2003;15:1165-1170.

21 Ueland T, Bollerslev J, Godang K, Muller F, Froland SS, Aukrust P: Increased serum osteoprotegerin in disorders characterized by persistent immune activation or glucocorticoid excess - possible role in bone homeostasis. Eur $\mathrm{J}$ Endocrinol 2001;145:685-690.

22 Park KM, Hay JE, Lee SG, Lee YJ, Wiesner RH, Porayko MK, Krom RA: Bone loss after orthotopic liver transplantation: FK 506 versus cyclosporine. Transplant Proc 1996;28: 1738-1740.

23 Goffin E, Devogelaer JP, Depresseux G, Squifflet JP, Pirson Y: Osteoporosis after organ transplantation. Lancet 2001;357:1623.

-24 Rubin MR, Bilezikian JP: Clinical review 151: the role of parathyroid hormone in the pathogenesis of glucocorticoid-induced osteoporosis: a re-examination of the evidence. J Clin Endocrinol Metab 2002;87:4033-4041. 
-25 Hahn TJ, Halstead LR, Baran DT: Effects off short term glucocorticoid administration on intestinal calcium absorption and circulating vitamin D metabolite concentrations in man. J Clin Endocrinol Metab 1981;52:111-115.

-26 van der Eerden BC, Karperien M, Wit JM: Systemic and local regulation of the growth plate. Endocr Rev 2003;24:782-801.

-27 Leinung MC, Zimmerman D: Cushing's disease in children. Endocrinol Metab Clin North Am 1994;23:629-639.

-28 Askari A, Vignos PJ Jr, Moskowitz RW: Steroid myopathy in connective tissue disease. Am J Med 1976;61:485-492.

$\checkmark 29$ Rauch F, Schoenau E: The developing bone: slave or master of its cells and molecules? Pediatr Res 2001;50:309-314

>30 Ballinger AB, Savage MO, Sanderson IR: Delayed puberty associated with inflammatory bowel disease. Pediatr Res 2003;53:205-210.

31 Simon D: Puberty in chronically diseased patients. Horm Res 2002;57(suppl 2):53-56.

\32 Kaltsas GA, Isidori AM, Kola BP, Skelly RH, Chew SL, Jenkins PJ, Monson JP, Grossman AB, Besser GM: The value of the low-dose dexamethasone suppression test in the differential diagnosis of hyperandrogenism in women. $\mathrm{J}$ Clin Endocrinol Metab 2003;88:2634-2643.

$\checkmark 33$ Welsh TH Jr, Bambino TH, Hsueh AJ: Mechanism of glucocorticoid-induced suppression of testicular androgen biosynthesis in vitro. Biol Reprod 1982;27:1138-1146.

$>34$ Frost HM: On the estrogen-bone relationship and postmenopausal bone loss: a new model. J Bone Miner Res 1999;14:1473-1477.

-35 Reid IR, Evans MC, Stapleton J: Lateral spine densitometry is a more sensitive indicator of glucocorticoid-induced bone loss. J Bone Miner Res 1992; 7:1221-1225.

>36 Henderson NK, Sambrook PN, Kelly PJ, Macdonald P, Keogh AM, Spratt P, Eisman JA: Bone mineral loss and recovery after cardiac transplantation. Lancet 1995;346:905.

-37 LoCascio V, Ballanti P, Milani S, Bertoldo F, LoCascio C, Zanolin EM, Bonucci E: A histomorphometric long-term longitudinal study of trabecular bone loss in glucocorticoid-treated patients: prednisone versus deflazacort. Calcif Tissue Int 1998;62:199-204.

>38 Laan RF, van Riel PL, van de Putte LB, van Erning LJ, van't Hof MA, Lemmens JA: Lowdose prednisone induces rapid reversible axial bone loss in patients with rheumatoid arthritis. A randomized, controlled study. Ann Intern Med 1993;119:963-968.

-39 Rizzato G, Montemurro L: Reversibility of exogenous corticosteroid-induced bone loss. Eur Respir J 1993;6:116-119.

-40 Gafni RI, McCarthy EF, Hatcher T, Meyers JL, Inoue N, Reddy C, Weise M, Barnes KM, Abad V, Baron J: Recovery from osteoporosis through skeletal growth: early bone mass acquisition has little effect on adult bone density. FASEB J 2002; 16:736-738.

-41 Henderson RC, Madsen CD, Davis C, Gold $\mathrm{SH}$ : Longitudinal evaluation of bone mineral density in children receiving chemotherapy. $\mathrm{J}$ Pediatr Hematol Oncol 1998;20:322-326.
42 Bianchi ML: Glucocorticoids and bone: some general remarks and some special observations in pediatric patients. Calcif Tissue Int 2002;70: 384-390.

43 Mandel K, Atkinson S, Barr RD, Pencharz P: Skeletal morbidity in childhood acute lymphoblastic leukemia. J Clin Oncol 2004;22:12151221.

44 Peel NF, Moore DJ, Barrington NA, Bax DE, Eastell R: Risk of vertebral fracture and relationship to bone mineral density in steroid treated rheumatoid arthritis. Ann Rheum Dis 1995;54:801-806.

45 Genant HK, Cooper C, Poor G, Reid I, Ehrlich G, Kanis J, Nordin BE, Barrett-Connor E, Black D, Bonjour JP, Dawson-Hughes B, Delmas PD, Dequeker J, Ragi Eis S, Gennari C, Johnell O, Johnston CC Jr, Lau EM, Liberman UA, Lindsay R, Martin TJ, Masri B, Mautalen CA, Meunier PJ, Khaltaev N, et al: Interim report and recommendations of the World Health Organization Task-Force for Osteoporosis. Osteoporos Int 1999;10:259-264.

46 Jones IE, Taylor RW, Williams SM, Manning PJ, Goulding A: Four-year gain in bone mineral in girls with and without past forearm fractures: a DXA study. Dual energy X-ray absorptiometry. J Bone Miner Res 2002; 17: 1065-1072.

-47 Leonard MB, Herskovitz RM, Howard KM, Baldassano RN, Burnham JM, Zemel BS: Crohn's disease in childhood is associated with decreased trabecular density, cortical dimensions and muscle mass. J Bone Miner Res 2004; 19:1137.

48 Pouw EM, Prummel MF, Oosting H, Roos $\mathrm{CM}$, Endert E: Beclomethasone inhalation decreases serum osteocalcin concentrations. $\mathrm{Br}$ Med J 1991;302:627-628.

49 Sambrook PN, Eisman JA, Yeates MG, Pocock NA, Eberl S, Champion GD: Osteoporosis in rheumatoid arthritis: safety of low dose corticosteroids. Ann Rheum Dis 1986;45:950953.

50 Buckley LM, Leib ES, Cartularo KS, Vacek PM, Cooper SM: Effects of low dose corticosteroids on the bone mineral density of patients with rheumatoid arthritis. J Rheumatol 1995; 22:1055-1059.

51 Gluck OS, Murphy WA, Hahn TJ, Hahn B: Bone loss in adults receiving alternate day glucocorticoid therapy. A comparison with daily therapy. Arthritis Rheum 1981;24:892-898.

52 Ferraris JR, Pasqualini T, Legal S, Sorroche P, Galich AM, Pennisi P, Domene H, Jasper H: Effect of deflazacort versus methylprednisone on growth, body composition, lipid profile, and bone mass after renal transplantation. The Deflazacort Study Group. Pediatr Nephrol 2000; 14:682-688.

53 Loftus J, Allen R, Hesp R, David J, Reid DM, Wright DJ, Green JR, Reeve J, Ansell BM, Woo PM: Randomized, double-blind trial of deflazacort versus prednisone in juvenile chronic (or rheumatoid) arthritis: a relatively bone-sparing effect of deflazacort. Pediatrics 1991;88:428-436.
54 Chabot G, Alos N, Brousseau Y, Dube J, Delvin E, Filiatreault M, Vanasse M: Osteoporosis and fractures in children with Duchenne's muscular dystrophy treated with glucocorticoids: a longitudinal study. J Bone Miner Res 2002; 17:F419.

55 Larson CM, Henderson RC: Bone mineral density and fractures in boys with Duchenne muscular dystrophy. J Pediatr Orthop 2000; 20:71-74.

56 Rao R, Gregson RK, Jones AC, Miles EA, Campbell MJ, Warner JO: Systemic effects of inhaled corticosteroids on growth and bone turnover in childhood asthma: a comparison of fluticasone with beclomethasone. Eur Respir J 1999; 13:87-94.

57 Martinati LC, Bertoldo F, Gasperi E, Fortunati P, Lo Cascio V, Boner AL: Longitudinal evaluation of bone mass in asthmatic children treated with inhaled beclomethasone dipropionate or cromolyn sodium. Allergy 1998;53: 705-708.

$>58$ Agertoft L, Pedersen S: Bone mineral density in children with asthma receiving long-term treatment with inhaled budesonide. Am J Respir Crit Care Med 1998;157:178-183.

59 Heuck C, Wolthers OD, Kollerup G, Hansen M, Teisner B: Adverse effects of inhaled budesonide (800 micrograms) on growth and collagen turnover in children with asthma: a double-blind comparison of once-daily versus twice-daily administration. J Pediatr 1998; 133:608-612.

60 Allen HD, Thong IG, Clifton-Bligh P, Holmes S, Nery L, Wilson KB: Effects of high-dose inhaled corticosteroids on bone metabolism in prepubertal children with asthma. Pediatr Pulmonol 2000;29:188-193.

61 Brennan BM, Rahim A, Adams JA, Eden OB, Shalet SM: Reduced bone mineral density in young adults following cure of acute lymphoblastic leukaemia in childhood. Br J Cancer 1999; 79:1859-1863.

62 Falcini F, Trapani S, Civinini R, Capone A, Ermini M, Bartolozzi G: The primary role of steroids on the osteoporosis in juvenile rheumatoid patients evaluated by dual energy Xray absorptiometry. J Endocrinol Invest 1996; 19:165-169.

63 Kotaniemi A, Savolainen A, Kroger H, Kautiainen $\mathrm{H}$, Isomaki $\mathrm{H}$ : Weight-bearing physical activity, calcium intake, systemic glucocorticoids, chronic inflammation, and body constitution as determinants of lumbar and femoral bone mineral in juvenile chronic arthritis. Scand J Rheumatol 1999;28:19-26.

64 Leonard MB, Feldman HI, Shults J, Zemel BS, Foster BJ, Stallings VA: Long-term, highdose glucocorticoids and bone mineral content in childhood glucocorticoid-sensitive nephrotic syndrome. N Engl J Med 2004;351: 868-875.

65 Schoenau E, Neu CM, Beck B, Manz F, Rauch $\mathrm{F}$ : Bone mineral content per muscle cross-sectional area as an index of the functional muscle-bone unit. J Bone Miner Res 2002;17: 1095-1101. 
-66 Crabtree NJ, Kibirige MS, Fordham JN, Banks LM, Muntoni F, Chinn D, Boivin CM, Shaw NJ: The relationship between lean body mass and bone mineral content in paediatric health and disease. Bone 2004;35: 965-972.

-67 Frost HM: Bone 'mass' and the 'mechanostat': a proposal. Anat Rec 1987;219:1-9.

-68 Sumnik Z, Land C, Rieger-Wettengl G, Korber F, Stabrey A, Schoenau E: Effect of pamidronate treatment on vertebral deformity in children with primary osteoporosis. A pilot study using radiographic morphometry. Horm Res 2004;61:137-142.

69 Feber J, Ward LM, Rauch F, Filler G: Bone mineral density by DXA may not be reduced in children with bone fragility due to steroidresistant nephrotic syndrome. 7th Symposium on Growth and Development in Children with Chronic Kidney Disease Heidelberg, Germany, 2004.

-70 Adachi JD, Bensen WG, Bianchi F, Cividino A, Pillersdorf S, Sebaldt RJ, Tugwell P, Gordon M, Steele M, Webber C, Goldsmith CH: Vitamin D and calcium in the prevention of corticosteroid induced osteoporosis: a 3 year followup. J Rheumatol 1996;23:995-1000.

71 Lukert BP: Glucocorticoid-induced osteoporosis; in Favus MJ (ed): Primer on the Metabolic Bone Diseases and Disorders of Mineral Metabolism. Philadelphia, Lippincott Williams \& Wilkins, 1999, pp 292-296.

-72 Hall GM, Daniels M, Huskisson EC, Spector TD: A randomised controlled trial of the effect of hormone replacement therapy on disease activity in postmenopausal rheumatoid arthritis. Ann Rheum Dis 1994;53:112-116.

-73 Luengo M, Pons F, Martinez de Osaba MJ, Picado C: Prevention of further bone mass loss by nasal calcitonin in patients on long term glucocorticoid therapy for asthma: a two year follow up study. Thorax 1994;49:10991102.

74 Kotaniemi A, Piirainen H, Paimela L, Leirisalo-Repo M, Uoti-Reilama K, Lahdentausta $P$, Ruotsalainen P, Kataja M, Vaisanen E, Kurki P: Is continuous intranasal salmon calcitonin effective in treating axial bone loss in patients with active rheumatoid arthritis receiving low dose glucocorticoid therapy? J Rheumatol 1996;23:1875-1879.

75 Adachi JD, Saag KG, Delmas PD, Liberman UA, Emkey RD, Seeman E, Lane NE, Kaufman JM, Poubelle PE, Hawkins F, Correa-Rotter R, Menkes CJ, Rodriguez-Portales JA, Schnitzer TJ, Block JA, Wing J, McIlwain HH, Westhovens R, Brown J, Melo-Gomes JA, Gruber BL, Yanover MJ, Leite MO, Siminoski KG, Nevitt MC, Sharp JT, Malice MP, Dumortier T, Czachur M, Carofano W, Daifotis A: Two-year effects of alendronate on bone mineral density and vertebral fracture in patients receiving glucocorticoids: a randomized, double-blind, placebo-controlled extension trial. Arthritis Rheum 2001;44: 202-211.
76 Wallach S, Cohen S, Reid DM, Hughes RA, Hosking DJ, Laan RF, Doherty SM, Maricic M, Rosen C, Brown J, Barton I, Chines AA: Effects of risedronate treatment on bone density and vertebral fracture in patients on corticosteroid therapy. Calcif Tissue Int 2000;67: 277-285.

-77 Nishioka T, Kurayama H, Yasuda T, Udagawa J, Matsumura C, Niimi H: Nasal administration of salmon calcitonin for prevention of glucocorticoid-induced osteoporosis in children with nephrosis. J Pediatr 1991; 118:703-707.

78 Bianchi ML, Cimaz R, Bardare M, Zulian F, Lepore L, Boncompagni A, Galbiati E, Corona F, Luisetto G, Giuntini D, Picco P, Brandi ML, Falcini F: Efficacy and safety of alendronate for the treatment of osteoporosis in diffuse connective tissue diseases in children: a prospective multicenter study. Arthritis Rheum 2000; 43:1960-1966.

79 Geusens P, Menten J, Vosse D, Vanhoof J, van der Linden S: Recovery from severe glucocorticoid-induced osteoporosis in an adolescent boy. J Clin Densitom 2001;4:389-394.

80 Barr RD, Guo CY, Wiernikowski J, Webber C, Wright M, Atkinson S: Osteopenia in children with acute lymphoblastic leukemia: a pilot study of amelioration with Pamidronate. Med Pediatr Oncol 2002;39:44-46.

81 Noguera A, Ros JB, Pavia C, Alcover E, Valls C, Villaronga M, Gonzalez E: Bisphosphonates, a new treatment for glucocorticoid-induced osteoporosis in children. J Pediatr Endocrinol Metab 2003;16:529-536.

82 Rooney M, Davies UM, Reeve J, Preece M, Ansell BM, Woo PM: Bone mineral content and bone mineral metabolism: changes after growth hormone treatment in juvenile chronic arthritis. J Rheumatol 2000;27:1073-1081.

83 Fisher JE, Rogers MJ, Halasy JM, Luckman SP, Hughes DE, Masarachia PJ, Wesolowski G, Russell RG, Rodan GA, Reszka AA: Alendronate mechanism of action: geranylgeraniol, an intermediate in the mevalonate pathway, prevents inhibition of osteoclast formation, bone resorption, and kinase activation in vitro. Proc Natl Acad Sci USA 1999; 96:133-138.

84 Luckman SP, Coxon FP, Ebetino FH, Russell RG, Rogers MJ: Heterocycle-containing bisphosphonates cause apoptosis and inhibit bone resorption by preventing protein prenylation: evidence from structure-activity relationships in J774 macrophages. J Bone Miner Res 1998;13:1668-1678.

85 Glorieux FH, Bishop NJ, Plotkin H, Chabot G, Lanoue G, Travers R: Cyclic administration of pamidronate in children with severe osteogenesis imperfecta. N Engl J Med 1998;339:947952.

86 Astrom E, Soderhall S: Beneficial effect of long term intravenous bisphosphonate treatment of osteogenesis imperfecta. Arch Dis Child 2002; $86: 356-364$
87 Zacharin M, Bateman J: Pamidronate treatment of osteogenesis imperfecta - lack of correlation between clinical severity, age at onset of treatment, predicted collagen mutation and treatment response. J Pediatr Endocrinol Metab 2002;15:163-174.

88 Rauch F, Plotkin H, Zeitlin L, Glorieux FH: Bone mass, size, and density in children and adolescents with osteogenesis imperfecta: effect of intravenous pamidronate therapy. J Bone Miner Res 2003;18:610-614.

89 Rauch F, Plotkin H, Travers R, Zeitlin L, Glorieux FH: Osteogenesis imperfecta types I, III, and IV: effect of pamidronate therapy on bone and mineral metabolism. J Clin Endocrinol Metab 2003;88:986-992.

90 Montpetit K, Plotkin H, Rauch F, Bilodeau N, Cloutier S, Rabzel M, Glorieux FH: Rapid increase in grip force after start of pamidronate therapy in children and adolescents with severe osteogenesis imperfecta. Pediatrics 2003; 111(5 Pt 1):e601-e603.

-91 Rauch F, Travers R, Plotkin H, Glorieux FH: The effects of intravenous pamidronate on the bone tissue of children and adolescents with osteogenesis imperfecta. J Clin Invest 2002; 110:1293-1299.

92 Glorieux FH, Rauch F, Shapiro JR: Bisphosphonates in children with bone diseases. $\mathrm{N}$ Engl J Med 2003;349:2068-71.

93 Brumsen C, Hamdy NA, Papapoulos SE: Long-term effects of bisphosphonates on the growing skeleton. Studies of young patients with severe osteoporosis. Medicine (Baltimore) 1997;76:266-283.

94 Munns CF, Rauch F, Zeitlin L, Fassier F, Glorieux FH: Delayed osteotomy but not fracture healing in pediatric osteogenesis imperfecta patients receiving pamidronate. J Bone Miner Res 2004;19:1779-1786.

-95 Zeitlin L, Rauch F, Plotkin H, Glorieux FH: Height and weight development during four years of therapy with cyclical intravenous pamidronate in children and adolescents with osteogenesis imperfecta types I, III, and IV. Pediatrics 2003;111(5 Pt 1):1030-1036.

96 Rauch F, Glorieux FH: Osteogenesis imperfecta. Lancet 2004;363:1377-1385.

-97 Whyte MP, Wenkert D, Clements KL, McAlister WH, Mumm S: Bisphosphonate-induced osteopetrosis. N Engl J Med 2003;349:457463.

98 Ward LM, Denker AE, Porras A, Shugarts S, Kline W, Travers R, Mao C, Rauch F, Maes A, Larson P, Deutsch P, Glorieux FH: Single-dose pharmacokinetics and tolerability of alendronate 35- and 70-milligram tablets in children and adolescents with osteogenesis imperfecta type I. J Clin Endocrinol Metab 2005;90: 4051-4056.

-99 Sakkers R, Kok D, Engelbert R, van Dongen A, Jansen M, Pruijs H, Verbout A, Schweitzer D, Uiterwaal C: Skeletal effects and functional outcome with olpadronate in children with osteogenesis imperfecta: a 2-year randomised placebo-controlled study. Lancet 2004;363: 1427-1431. 
100 Jones G, Sambrook PN: Drug-induced disorders of bone metabolism. Incidence, management and avoidance. Drug Saf 1994;10:480489.

101 Stein B, Takizawa M, Katz I, Joffe I, Berlin J, Fallon M, Epstein S: Salmon calcitonin prevents cyclosporin-A-induced high turnover bone loss. Endocrinology 1991;129:92-98.

102 Mutoh S, Takeshita N, Yoshino T, Yamaguchi I: Characterization of heparin-induced osteopenia in rats. Endocrinology 1993;133: 2743-2748.

103 Ramuz O, Bourhis J, Mornex F: Late effects of radiations on mature and growing bone. Cancer Radiother 1997;1:801-809.
104 Cromer B, Harel Z: Adolescents: at increased risk for osteoporosis? Clin Pediatr (Phila) 2000;39:565-574.

- 105 Yanovski JA, Rose SR, Municchi G, Pescovitz OH, Hill SC, Cassorla FG, Cutler GB Jr: Treatment with a luteinizing hormone-releasing hormone agonist in adolescents with short stature. N Engl J Med 2003;348:908-917.

106 Radetti G, Castellan C, Tato L, Platter K, Gentili L, Adami S: Bone mineral density in children and adolescent females treated with high doses of $L$-thyroxine. Horm Res 1993; 39:127-131.
107 Rizzoli R, Poser J, Burgi U: Nuclear thyroid hormone receptors in cultured bone cells. Metabolism 1986;35:71-74.

108 Britto JM, Fenton AJ, Holloway WR, Nicholson GC: Osteoblasts mediate thyroid hormone stimulation of osteoclastic bone resorption. Endocrinology 1994;134:169-176.

109 Rieger-Wettengl G, Tutlewski B, Stabrey A, Rauch F, Herkenrath P, Schauseil-Zipf U, Schoenau E: Analysis of the musculoskeletal system in children and adolescents receiving anticonvulsant monotherapy with valproic acid or carbamazepine. Pediatrics 2001;108: E107. 